\section{Museet for Dansk Bladtegning i Brasilien}

af bladtegner Claus Seidel, Museet for Dansk Bladtegning, Det Kongelige Bibliotek

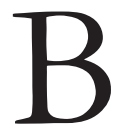
ladtegnermuseets store nordiske temaudstilling om "Klimaet", der vistes i Det Kongelige Bibliotek under COP15's klima-konference i december 2009 i København og dér blev en meget besøgt udstilling, kunne ses i Brasiliens hovedstad Brasilia i vinteren 2010/2011, i byens busterminal, Novo Terminal Rodoviário.

\section{$\mathrm{I}$} nitiativet kom fra Det Danske Kulturinstitut i Rio de Janeiro, som foreslog de fire nordiske ambassader i Brasilia at præsentere udstillingen et sted i den store hovedstad for at markere - og måske provokere - Klimakonferencen COP16 i Cancún, Mexico.

Ambassaderne var begejstrede for ideen og kulturinstituttet spurgte os, om det kunne lade sig gøre

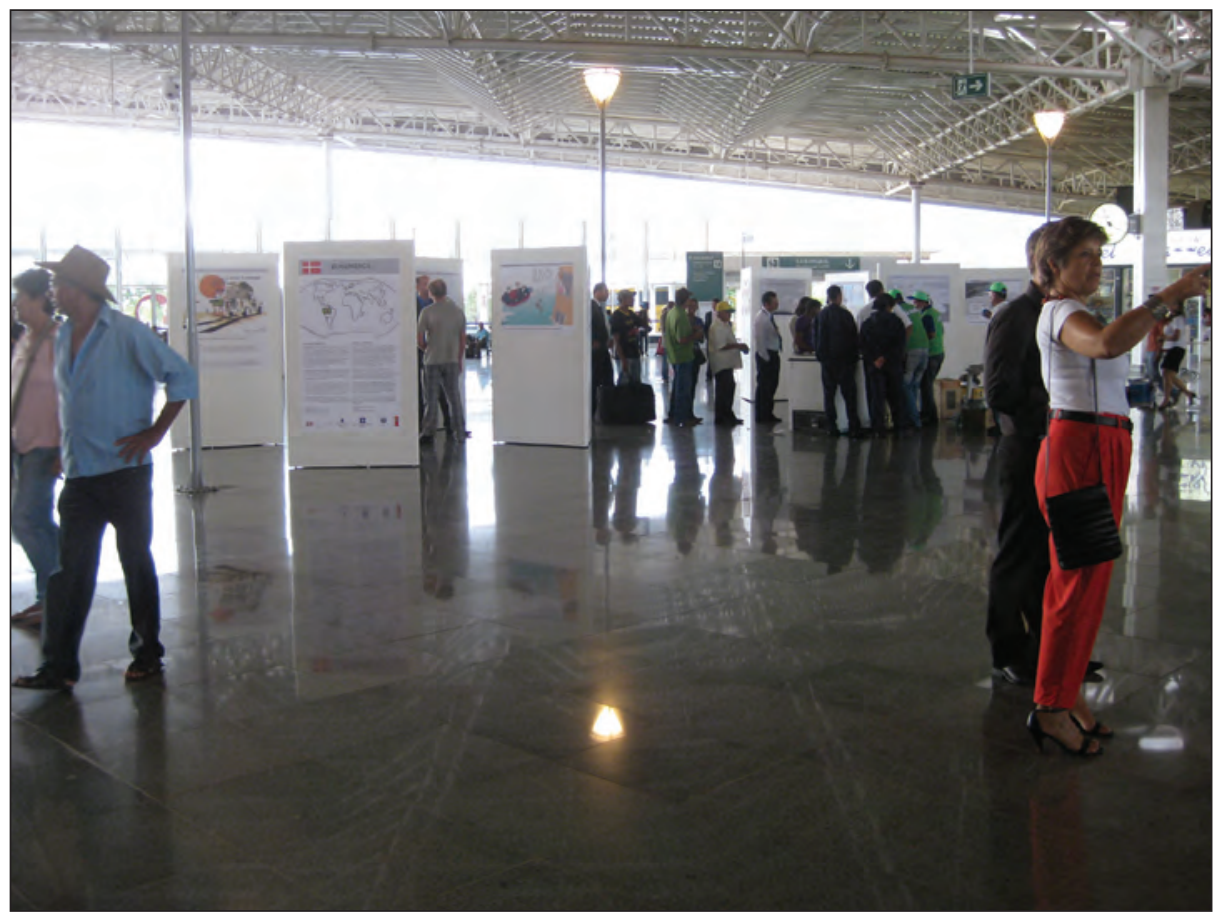

Brasilias busterminal lagde i vinteren 2010/2011 rum til Museet for Dansk Bladtegnings store klima-udstilling. Terminalen er en stor, nybygget og meget dristigt designet rektangular bygning med busholdepladser og afgangs/ ankomst-faciliteter $i$ den ene side og indgangs- og udgangsfaciliteter $i$ den anden. Den er på storrelse med halvdelen af Kobenhavns Hovedbanegärds afgangshal og betjener Brasilias ca. 3 millioner indbyggere. Hallen må betegnes som meget velegnet til udstillingsbrug. Fot. Claus Seidel.

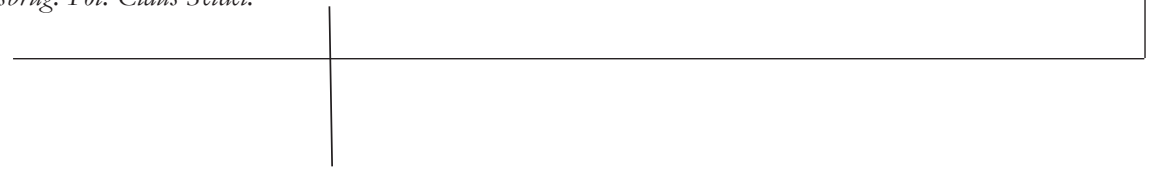




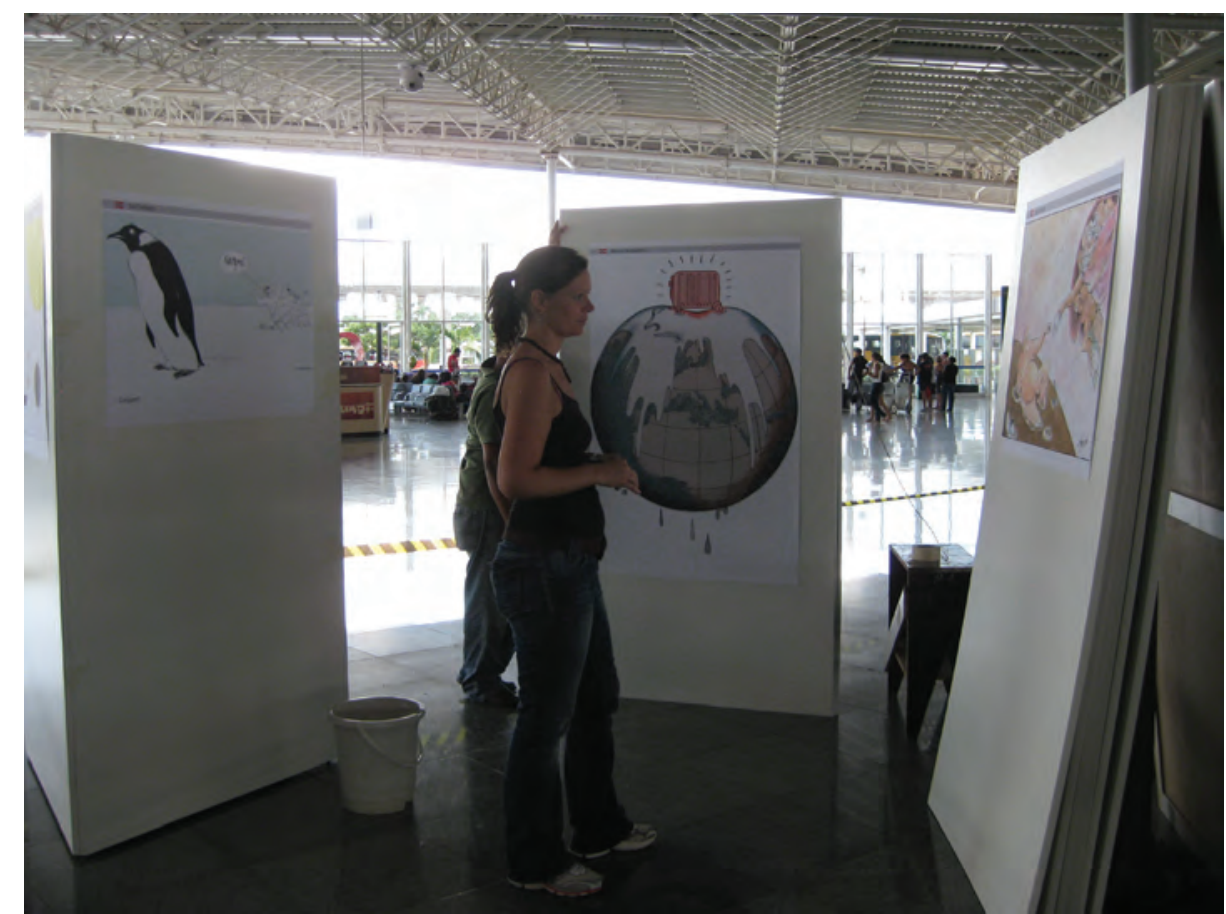

De skandinaviske ambassader havde fået designet trekantede udstillingstarne i storrelsen $2 \mathrm{~m}$ i hojden og $1.20 \mathrm{~m}$ $i$ bredden. Meget flotte, men vanskelige at skrue sammen og demontere - og derfor umulige til genbrug, bvilket var meget upraktisk, idet udstillingen senere skulle vises andre steder i Brasilien. Fot. Claus Seidel.

at lade udstillingen genopstå præcis som i Diamanten - dog gerne forøget med finske tegnere således, at Finland, Sverige, Norge og Danmark blev ligeligt repræsenteret.

Bladtegnermuseet sagde ja tak og vi gik i gang med at søge fonde, så vi kunne bære en del af den økonomiske byrde.

Finnerne blev kontaktet og tryllede fremragende bladtegninger over temaet frem, og Det Kongelige Biblioteks Fotografiske Atelier satte printermaskinen i sving.

Penge kom fra de ansøgte fonde og med de mange prints under armen, og tapetklister og kost i kufferten, rejste Pelle Sadolin og undertegnede af sted mod de varme himmelstrøg, hvor vi ankom efter 20 timers flyvetur.

Efter at have fået smidt

Udstillingen under opbygning. Pelle Sadolin tager sig et lille hvil i tropevarmen. Fot. Claus Seidel.

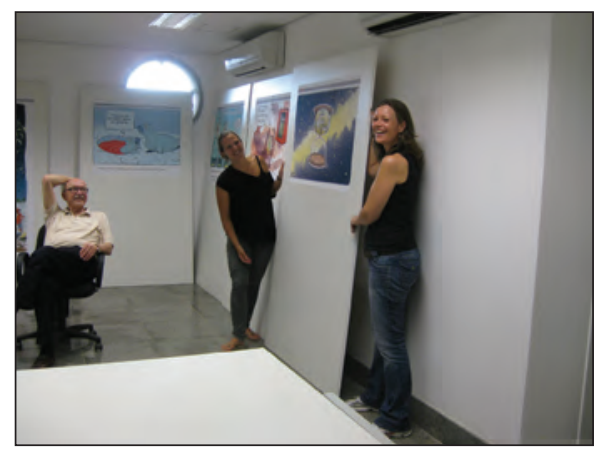




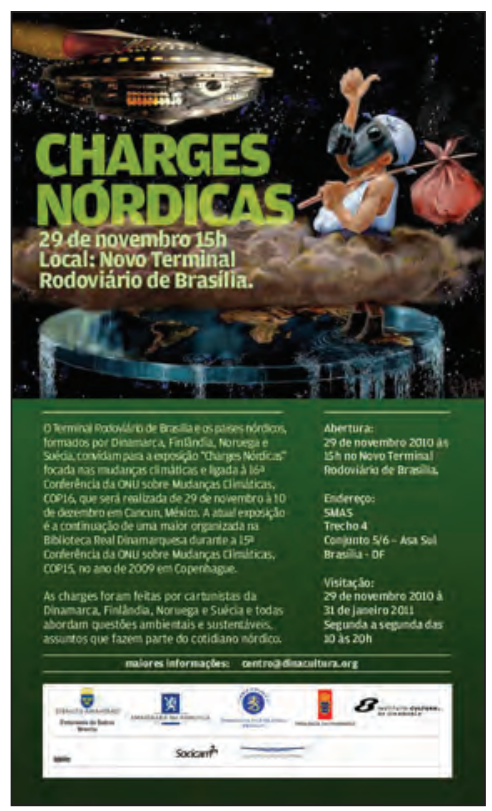

bagagen af hos den danske ambassadør, kørte ambassadechaufføren os til byens nye og supermoderne busterminal, hvor udstillingen skulle finde sted. Fantastisk sted, hvor tusinder af brasilianere dagligt tålmodigt venter på deres bus, der skal fragte dem rundt i det store land. Brasilien har ingen tog.

Desværre var ingen af de afta-

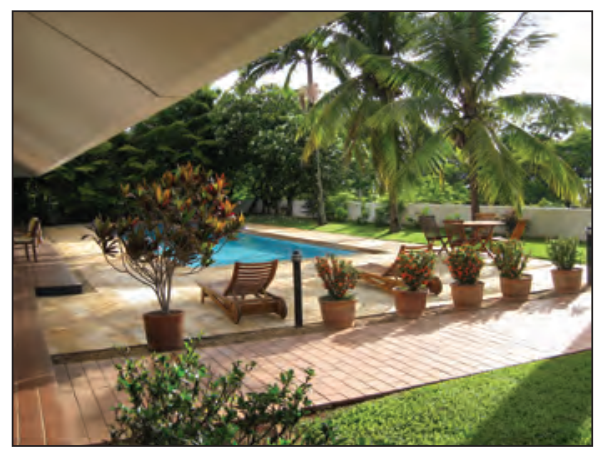

Museet for Dansk. Bladtegnings to rejsende reprasentanter, Claus Seidel og Pelle Sadolin, blev indkvarteret under fine forbold $i$ den danske ambassade. Fot. Claus Seidel.

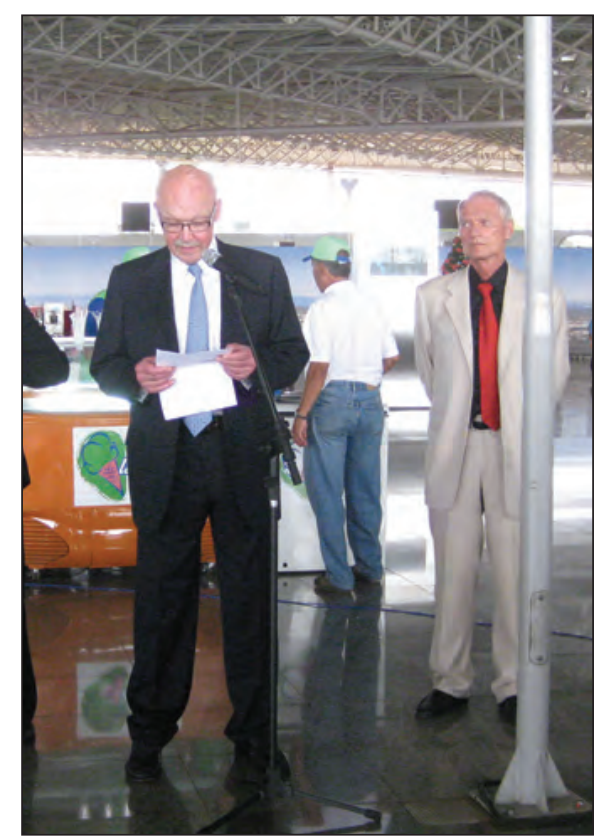

Ferniseringen fandt sted som planlagt 29. november 2010, med taler af busterminalens direktor (det var forste udstilling på stedet), den danske ambassador Svend Roed Nielsen (t.h.) og Pelle Sadolin (t.v.). Fot. Claus Seidel.

ler, der var indgået med kulturinstituttet $\mathrm{og}$ videre til deres håndværkere, ført ud i livet.

De 48 vægge, der skulle blive til 16 tårne og rumme de mange tegninger, var man stadig i gang med at producere, og da de endelig begyndte at dukke op, var de umulige at tapetsere op på og endnu værre at samle, og de såkaldte håndværkere udeblev eller kom lallende 8 timer efter aftaletidspunktet. Alt var kaos og sveden piblede af os. Brasilien har tropeklima og regnskov overalt.

Vi gik i gang og satte hele den danske og en god del af den finske ambassade i sving, og sikkert for første gang i sit diplomat-liv stod den danske 


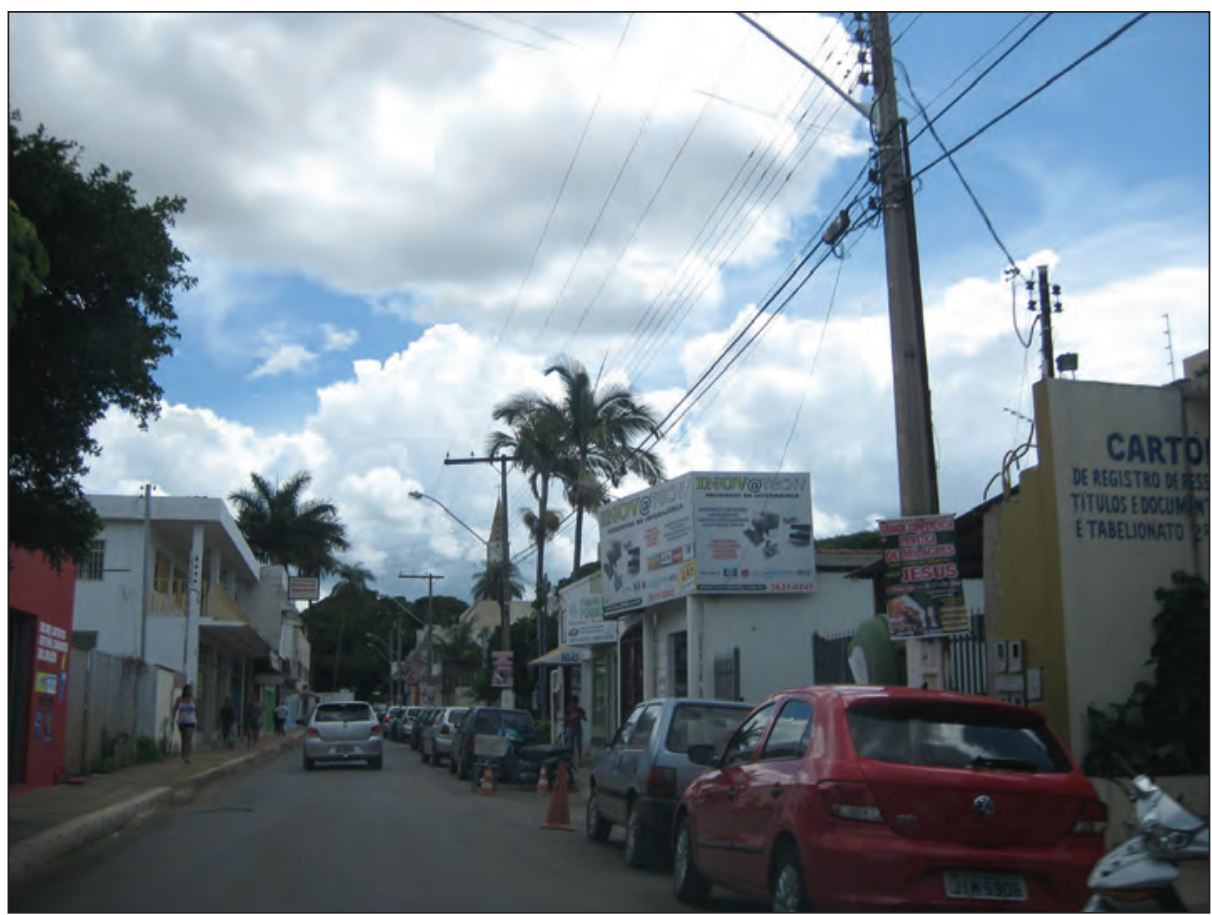

En anden side af Brasilia. Fot. Claus Seidel.

ambassadør til sent søndag aften og skruede 800 skruer i udstillingsvæggene. Og han var god til det.

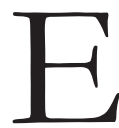
n time før de fire ambassader hver især skulle klippe det røde bånd over, lagde vi sidste hånd på udstillingen. En erfaring rigere på mange måder, men også med en flot oplevelse af et smukt land.

Udstillingen skal senere vises i Rio de Janeiro og San Paolo.

Brasilianerne morede sig fra den forste tegning blev hængt op og det var tydeligt, at de var interesserede og afgjort fangede den nordiske form for humor.

Næste dag, inden flyet lettede med Pelle og jeg, nåede vi at blive kørt en lille tur ud i det store landskab og fik lige lov til at dufte til den brasilianske regnskov. Ca. $10.000 \mathrm{~km}$ senere var vi tilbage i Danmark og til en temperaturforskel på 40 grader.

- Udstillingen blev, da den i februar 2011 sluttede i Busterminalen, flyttet til Brasilias store internationale lufthavn, hvor endnu flere rejsende fra ind- og udland kunne se de nordiske bladtegneres klimategninger. 